www.nature.com/pj

\title{
Cell-adhesive hydrogels composed of peptide nanofibers responsive to biological ions
}

\author{
Toshiki Sawada ${ }^{1}$, Masaki Tsuchiya, Tsuyoshi Takahashi ${ }^{2}$, Hiroshi Tsutsumi and Hisakazu Mihara
}

Novel calcium ion $\left(\mathrm{Ca}^{2+}\right)$-responsive hydrogels composed of designed $\beta$-sheet peptides were constructed. As the novel designed peptide, E1Y9, has a Glu residue to interact with $\mathrm{Ca}^{2+}$, the peptide in the sol-state self-assembled into hydrogels in the presence of $\mathrm{Ca}^{2+}$. The hydrogelation did not occur in the absence of $\mathrm{Ca}^{2+}$; therefore, $\mathrm{Ca}^{2+}$-dependent hydrogelation was achieved by the molecular design. The hydrogelation from the viscous sol-state solution can be induced by a slower self-assembly process of the $\beta$-sheet peptide involving a rapid process of $\mathrm{Ca}^{2}+$ binding. When the sol-state peptide solution was injected with $\mathrm{Ca}^{2+}$, gel drops and strings with desired shapes could be constructed. Different cell lines can be cultured on the hydrogel, demonstrating its low toxicity, which is comparable to commercially available microtiter plate surfaces for cell culture. Furthermore, the hydrogels showed a high cell-adhesive ability that was similar in magnitude to fibronectin, which is a native cell-adhesive protein. The $\mathrm{Ca}^{2+}$-responsive peptide nanofiber-based hydrogelation system will facilitate novel studies exploiting self-assembling peptide nanomaterials that will lead to cell-based technology, such as three-dimensional cell culturing.

Polymer Journal (2012) 44, 651-657; doi:10.1038/pj.2012.48; published online 4 April 2012

Keywords: cell adhesion; hydrogel; nanofiber; peptide self-assembly; stimuli responsive material

\section{INTRODUCTION}

The study of the self-assembled properties of biomolecules, such as peptides, proteins and nucleic acids, has developed in recent years into an attractive and diverse research field involving nanostructured materials. ${ }^{1,2}$ In natural systems, peptides and proteins are spontaneously organized in supramolecular architectures through numerous weak interactions (noncovalent bonds), such as electrostatic interactions, hydrogen bonding, $\pi$-stacking, van der Waals interactions and hydrophobic effects. The ability of peptides and proteins to construct specific secondary structures provides a useful function for bioinspired material design that cannot be achieved with traditional organic molecules and polymers. ${ }^{3,4}$ Peptides act as excellent building blocks for nanomaterials because of their ease of design and synthesis, small size and stability; therefore, peptide-based molecular designs have been used for the formation of novel smart materials, such as fibers or tubes, ${ }^{5-8}$ fibrils, ${ }^{9,10}$ capsules, ${ }^{11,12}$ surfactants $^{13,14}$ and hydrogels. ${ }^{15-17}$ We have developed de novo designed short $\beta$-sheet peptides that self-assemble into nanofibers with a uniform width of ca $100 \mathrm{~nm}$ for potential applications ranging from scaffolds for protein immobilization to metal-biofusion materials. ${ }^{18-21}$ More recently, we found that surface-functionalized self-assembling nanofibers, using a short peptide composed of nine amino-acid residues (Y9 peptide, sequence: Ac-YEYKYEYKY-NH $\mathrm{N}_{2}$ ), could be good scaffold candidates for cell adhesion. ${ }^{22}$ In nature, cells are surrounded by a complex three-dimensional (3D) extracellular matrix, which affords a structural function and physical strength to cells. Thus, artificial extracellular matrices, cell scaffolds, are fundamental to provide similar environments to the biological systems and also to form the required structures for tissue engineering. Self-assembling peptide hydrogels with properties responsive to local environmental stimuli lead to materials suitable for a wide range of biomedical applications. ${ }^{23}$ As peptide interactions can be controlled by external stimuli, such as $\mathrm{pH}$, ionic strength, temperature, light or the presence of small molecules, peptides could act as components for stimuli-responsive hydrogels.

In contrast, amino acids, such as His, Cys, Met, Glu, and/or Asp, interact with biological metal ions specifically to induce structural changes of proteins and to form supramolecular architectures. In particular, calcium is essential for living organisms, especially in cell biology, in which movement of the calcium ion $\left(\mathrm{Ca}^{2+}\right)$ into and out of the endoplasmic reticulum functions as a signal for a number of cellular processes. Therefore, it might be possible to use hydrogels that respond to $\mathrm{Ca}^{2+}$ to construct exquisite scaffolds for cell engineering. In this study, we report the construction of a self-assembling peptidebased nanofiber and hydrogel system that is triggered by $\mathrm{Ca}^{2+}$ binding. Generally, a carboxylic group in Glu that is known to interact with $\mathrm{Ca}^{2+}$ was conjugated to the designed $\beta$-sheet Y9 peptides. The self-assembling ability of $\mathrm{Y} 9$ peptides is expected to be enhanced by the coordination of $\mathrm{Ca}^{2+}$ with intermolecular Glu residues. The novel Glu-conjugated designed peptides were self- 
assembled into highly networked peptide nanofibers, and the nanofiber formations were strongly dependent on the presence of $\mathrm{Ca}^{2+}$. Higher concentrations of the peptide solutions in the presence of $\mathrm{Ca}^{2+}$ resulted in the formation of self-supporting hydrogels. Furthermore, the injection of the peptide solutions into $\mathrm{Ca}^{2+}$ solutions resulted in the construction of gel strings that can be transformed into various desired shapes. Cell culture experiments on hydrogels composed of the designed peptide nanofibers conjugated with the cell-adhesive peptide (RGDS) suggested that the peptides could act as scaffolds for celladhesive nanomaterials. Furthermore, adhesion cells on the peptide gel strings were well spreadout and differentiated with a high rate of survival. The molecular design-based concept will lead to attractive technology that uses the novel strategy involving cell-adhesive peptide nanofiber-based stimuli-responsive materials.

\section{MATERIALS AND METHODS}

\section{Peptide synthesis}

Peptides were synthesized by a conventional solid-phase method by using a 9-fluorenylmethyloxycarbonyl (Fmoc) strategy. ${ }^{24}$ The peptide chains were assembled on an NH-SAL-PEG resin (purchased from Watanabe Chemical Industries, Hiroshima, Japan) ( $N$-termini were acetylated and $C$-termini were amidated) with Fmoc amino-acid derivatives (3 equiv), $\mathrm{N}, \mathrm{N}$ diisopropylethylamine (DIEA, 6 equiv) and 2-(1H-Benzotriazol-1-yl)-1,1,3,3tetramethyluronium hexafluorophosphate (3 equiv) in $\mathrm{N}$-methylpyrrolidone (NMP) for coupling and piperidine (20\%)/NMP for Fmoc removal. In the case of coupling, 2-(aminoethoxy) ethoxy acetic acid (Aeea), 2-(1H-9-azabenzotriazole-1-yl)-1,1,3,3-tetramethyluroniumhexafluorophosphate (HATU, 1.5 equiv) and 3 equiv of DIEA were used. To cleave the peptide from the resin and remove the side-chain protecting groups, the peptide resin was treated with trifluoroacetic acid (TFA)/triisopropylsilane/water (95/2.5/2.5). All peptides were purified by reverse-phase HPLC on a Cosmosil 5C18-AR-II packedcolumn $\left(10 \times 250 \mathrm{~mm}^{2}\right)$ with a linear gradient of acetonitrile $/ 0.1 \%$ TFA at a flow rate of $3.0 \mathrm{ml} \mathrm{min}^{-1}$. The peptides were identified satisfactorily by liquid chromatography-electron spray ionization mass spectrometry on a Shimadzu LCMS-2010 (Shimadzu, Tokyo, Japan). Synthesized peptides showed over 95\% purities, and the observed mass values agreed with the calculated mass values within 1.0 mass unit (Y9: $M_{w \text { calcd }} 1389.5, m / z_{\text {calcd }}[\mathrm{M}+2 \mathrm{H}]^{2+} 695.8, \mathrm{~m} / \mathrm{z}_{\text {obsd }}[\mathrm{M}+2 \mathrm{H}]^{2+}$ 695.2; E1Y9: $M_{\text {w calcd }} 1518.6, \mathrm{~m} / \mathrm{z}_{\text {calcd }}[\mathrm{M}+2 \mathrm{H}]^{2+} 760.3, \mathrm{~m} / \mathrm{z}_{\text {obsd }}[\mathrm{M}+2 \mathrm{H}]^{2+} 760.3$; E2Y9: $M_{w \text { calcd }} 1647.7, m / z_{\text {calcd }}[\mathrm{M}+2 \mathrm{H}]^{2+} 824.9, \mathrm{~m} / z_{\text {obsd }}[\mathrm{M}+2 \mathrm{H}]^{2+} 825.3$; E3Y9: $M_{w \text { calcd }} 1776.8, \mathrm{~m} / \mathrm{z}_{\text {calcd }}[\mathrm{M}+2 \mathrm{H}]^{2}+889.4, \mathrm{~m} / \mathrm{z}_{\text {obsd }}[\mathrm{M}+2 \mathrm{H}]^{2+}$ 889.4; E4Y9: $M_{w \text { calcd }} 1906.0, m / z_{\text {calcd }}[\mathrm{M}+2 \mathrm{H}]^{2+} 954.0, \mathrm{~m} / \mathrm{z}_{\text {obsd }}[\mathrm{M}+2 \mathrm{H}]^{2+} 954.3$; E1Y9RGDS: $M_{w \text { calcd }} 2079.2, \mathrm{~m} / \mathrm{z}_{\text {calcd }}[\mathrm{M}+2 \mathrm{H}]^{2+} 1040.6, \mathrm{~m} / \mathrm{z}_{\mathrm{obsd}}[\mathrm{M}+2 \mathrm{H}]^{2+}$ 1040.8, $\left.\mathrm{m} / \mathrm{z}_{\text {calcd }}[\mathrm{M}+3 \mathrm{H}]^{3+} 694.1, \mathrm{~m} / \mathrm{z}_{\text {obsd }}[\mathrm{M}+3 \mathrm{H}]^{3+} 694.1\right)$.

\section{Infrared (IR) analysis}

Peptides were dissolved in ultrapure water with a concentration of $400 \mu \mathrm{M}$ and incubated for $48 \mathrm{~h}$ for nanofiber formation. Attenuated total reflection-IR spectra of peptide nanofibers were obtained using refractive surfaces (IRPrestige-21 with DuraSampl IR-II, Shimadzu, Tokyo, Japan) in air at ambient temperature. Interferograms were co-added 100 times and Fourier transformed at a resolution of $4 \mathrm{~cm}^{-1}$.

\section{Thioflavin $\mathrm{T}$ (ThT) binding analysis}

Peptides were dissolved in ultrapure water with a concentration of $400 \mu \mathrm{M}$ containing $0,0.4,0.8,1.6,4.0$ or $8.0 \mathrm{mM} \mathrm{Ca}^{2+}$. Then, $20 \mu \mathrm{l}$ of the mixed solution was added to $80 \mu \mathrm{l}$ of ThT solution with a concentration of $50 \mu \mathrm{M}$, and the mixtures were incubated for $1 \mathrm{~h}$ at ambient temperature. Subsequently, the amounts of peptide nanofibers were estimated by measuring the fluorescence intensities of binding ThT to the peptide nanofibers $\left(\lambda_{\mathrm{ex}}\right.$ and $\lambda_{\mathrm{em}}$ were 440 and $490 \mathrm{~nm}$, respectively).

\section{Transmission electron microscopic (TEM) observation}

A collodion-coated copper electron microscopic grid was placed coated-side down onto the peptide nanofiber solutions for $30 \mathrm{~min}$, and then the grid was floated onto a droplet of ultrapure water for $1 \mathrm{~min}$ for washing. The sample was negatively stained with $2 \%(\mathrm{w} / \mathrm{v})$ uranyl acetate for $1 \mathrm{~min}$. The grid was blotted and then allowed to dry gradually at ambient temperature overnight. All images were taken using a Hitachi H-7500 electron microscope (Hitachi, Tokyo, Japan) operating at $80 \mathrm{kV}$.

\section{Gel drop and string formation}

Peptide solutions $(2.0 \mathrm{wt} \%)$ were incubated for $48 \mathrm{~h}$, and then the solutions were mixed with Coomassie brilliant blue or ThT solution (the final concentrations of the peptide, Coomassie brilliant blue and ThT are $1.8 \mathrm{wt} \%, \quad 0.05 \mathrm{wt} \%$ and $150 \mu \mathrm{m}$, respectively). The mixed solutions were injected into $\mathrm{Ca}^{2+}$ solutions with a concentration of $100 \mathrm{mM}$. Then, the constructed hydrogels were observed by optical and fluorescence microscopies.

\section{Cell culture on peptide hydrogels}

3T3-L1 cells were cultured in Dulbecco's modified Eagle's medium supplemented with $10 \%$ fetal bovine serum and $100 \mathrm{Uml}^{-1}$ penicillin and $100 \mu \mathrm{g} \mathrm{ml}^{-1}$ streptomycin. PC12 cells were cultured in Dulbecco's modified Eagle's medium supplemented with $10 \%$ fetal bovine serum, 10\% Donor Horse Serum and $100 \mathrm{U} \mathrm{ml}^{-1}$ penicillin and $100 \mu \mathrm{g} \mathrm{ml}^{-1}$ streptomycin. The cells were seeded in a $10-\mathrm{cm}$ diameter Petri dish and allowed to grow until ca $50 \%$ (3T3-L1) or $80 \%$ (PC12) confluence. All incubations were performed at $37^{\circ} \mathrm{C}, 5 \% \mathrm{CO}_{2}$. RGDS conjugated E1Y9 (E1Y9-RGDS) and E1Y9 peptides were mixed with percentages of 0,10 or 20 of E1Y9-RGDS peptides. The mixed peptide solutions were incubated in 24-well tissue culture-treated plates (TCTP, Techno Plastic Products AG, Trasadingen, Switzerland) or injected with $500 \mu \mathrm{l}$ of $100 \mathrm{mM} \mathrm{Ca}^{2+}$ solutions in 24-well non-adhesive-treated plates (Asahi Glass, Tokyo, Japan) to construct flat gels or gel strings. Next, supernatants were removed and the gels were washed twice with serum-free medium. Cells in serum-free medium (5000 cells per $100 \mu \mathrm{l})$ were then applied to the well and incubated for several hours. Optical and fluorescence microscopic observations were used to evaluate cell adhesion and differentiation using Ti-U-PH-1 (Nikon, Tokyo, Japan). The percentages of strong adhered cells were estimated by comparing the changes in the fluorescence intensity before and after washing. For fluorescence observations, calceinacetoxymethyl ester (AM) and propidium iodide were used for the quantification of cell numbers and live/dead assays.

\section{RESULTS AND DISCUSSION}

\section{Spectroscopic characterization of peptide nanofiber}

One to four Glu residues were conjugated to the $N$-termini of Y9 peptide (one Glu residue-conjugated Y9 peptides were named E1Y9;

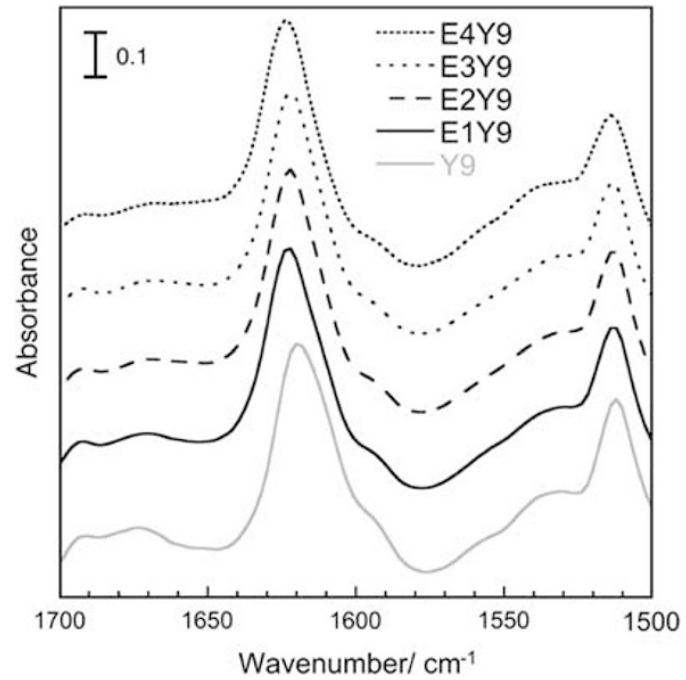

Figure 1 Secondary structural analyses of designed peptides. The infrared spectra of Y9 (Ac-YEYKYEYKY-NH${ }_{2}$ ) and EnY9 (Ac-En YEYKYEYKY-NH $\left.{ }_{2}\right)$ peptides are shown. All samples were measured at $400 \mu \mathrm{m}$ after $48 \mathrm{~h}$ incubation, and the scale of absorbance is shown in the figure. 
the other designed peptides were named similarly). The peptides were dissolved in water, and the solutions were incubated for $48 \mathrm{~h}$ at ambient temperature. To investigate the effect of Glu conjugation, the secondary structures of the peptides were analyzed by attenuated total reflection-IR. IR spectra of the amide I region $\left(1600-1700 \mathrm{~cm}^{-1}\right)$, which is primarily assigned to $\mathrm{C}=\mathrm{O}$ stretching, was attributed to $\beta$-sheet $\left(1620-1640 \mathrm{~cm}^{-1}\right), \alpha$-helix $\left(1648-1655 \mathrm{~cm}^{-1}\right)$ and antiparallel $\beta$-sheet $\left(1670-1690 \mathrm{~cm}^{-1}\right)^{25-27}$ structures. The IR spectra of $Y 9$ $\left(\right.$ Ac-YEYKYEYKY-NH ${ }_{2}$ ) and Glu-conjugated Y9 (EnY9, $n=1,2,3$, or 4) nanofibers are shown in Figure 1. The spectrum of the original Y 9 nanofibers shows a sharp band at $1625 \mathrm{~cm}^{-1}$ and a much smaller band at $1690 \mathrm{~cm}^{-1}$ corresponding to antiparallel $\beta$-sheet structures.

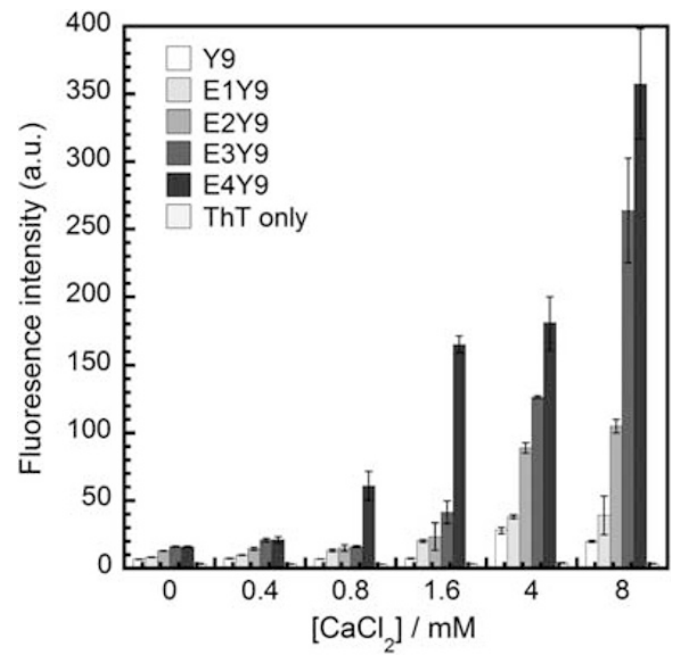

Figure 2 Thioflavin T (ThT)-binding analyses of peptide anofibers. The designed peptide $(100 \mu \mathrm{m})$ nanofibers and ThT $(40 \mu \mathrm{m})$ were incubated in water in the presence and absence of $\mathrm{Ca}^{2}+$ with various concentrations. The fluorescence intensity values of ThT binding to nanofibers were measured ( $\lambda_{\mathrm{ex}}$ and $\lambda_{\mathrm{em}}$ were 440 and $490 \mathrm{~nm}$, respectively) to estimate the number of peptide nanofibers. Control experiments without peptides were also performed (ThT only).
EnY9 peptides also show almost the same bands as Y9 peptides, as expected, demonstrating antiparallel $\beta$-sheet structures. Therefore, the conjugation of various Glu residues to Y9 peptides did not show significant effects on the secondary structural formation, which is important for construction of nanofibers, implying that the assembling abilities of EnY9 peptides are maintained. Circular dichroism measurements for analyzing the secondary structure of peptides could not be performed due to the strong exciton coupling of the Tyr residue in the nanofibers.

ThT-binding analysis was performed to evaluate the fiber-forming abilities of Y9 and EnY9 peptides in the absence and presence of $\mathrm{Ca}^{2+}$. ThT is widely used to visualize and quantify the presence of self-assembled $\beta$-sheet peptides or proteins due to the fluorescence enhancement caused when it binds to $\beta$-structures. In this case, ThT can be used to quantify the nanofiber formation. In the case without $\mathrm{Ca}^{2+}$, the fluorescence intensities of the peptides showed almost the same values and are larger than that of ThT alone (Figure 2), suggesting nanofiber formation. Addition of different concentrations of $\mathrm{Ca}^{2+}$ to the original Y9 peptide solution resulted in subtle fluorescence enhancement, suggesting that $\mathrm{Ca}^{2+}$ might interact with Glu residues in the original Y9 peptides. In contrast, EnY9 peptide solutions with $\mathrm{Ca}^{2+}$ showed much higher fluorescence intensities than solutions without $\mathrm{Ca}^{2+}$ and the original Y9. Furthermore, different fluorescence profiles in each peptide clearly suggested that organized $\beta$-structures and nanofibers were distinct from one another. In all EnY9 peptides, the fluorescence intensities were enhanced, and the intensities were dependent on the concentration of $\mathrm{Ca}^{2+}$, demonstrating that the nanofiber formation derived from $\beta$-structure construction was facilitated by the interaction with $\mathrm{Ca}^{2+}$. In particular, the maximum fluorescence intensity value of E4Y9 with $8 \mathrm{mM}$ of $\mathrm{Ca}^{2+}$ was 18 times greater than that of the original $\mathrm{Y} 9$ with the same concentration of $\mathrm{Ca}^{2+}$, demonstrating the efficacy of $\mathrm{Ca}^{2+}$ for the EnY9 assembly. The fluorescence intensities of the peptide solutions under the same $\mathrm{Ca}^{2+}$ concentration were dependent on the conjugated Glu residue numbers (the order of the fluorescence intensity values was $\mathrm{E} 4>\mathrm{E} 3>\mathrm{E} 2>\mathrm{E} 1>$ the original, in the presence of the same concentration of $\mathrm{Ca}^{2+}$ ), indicating that designed and
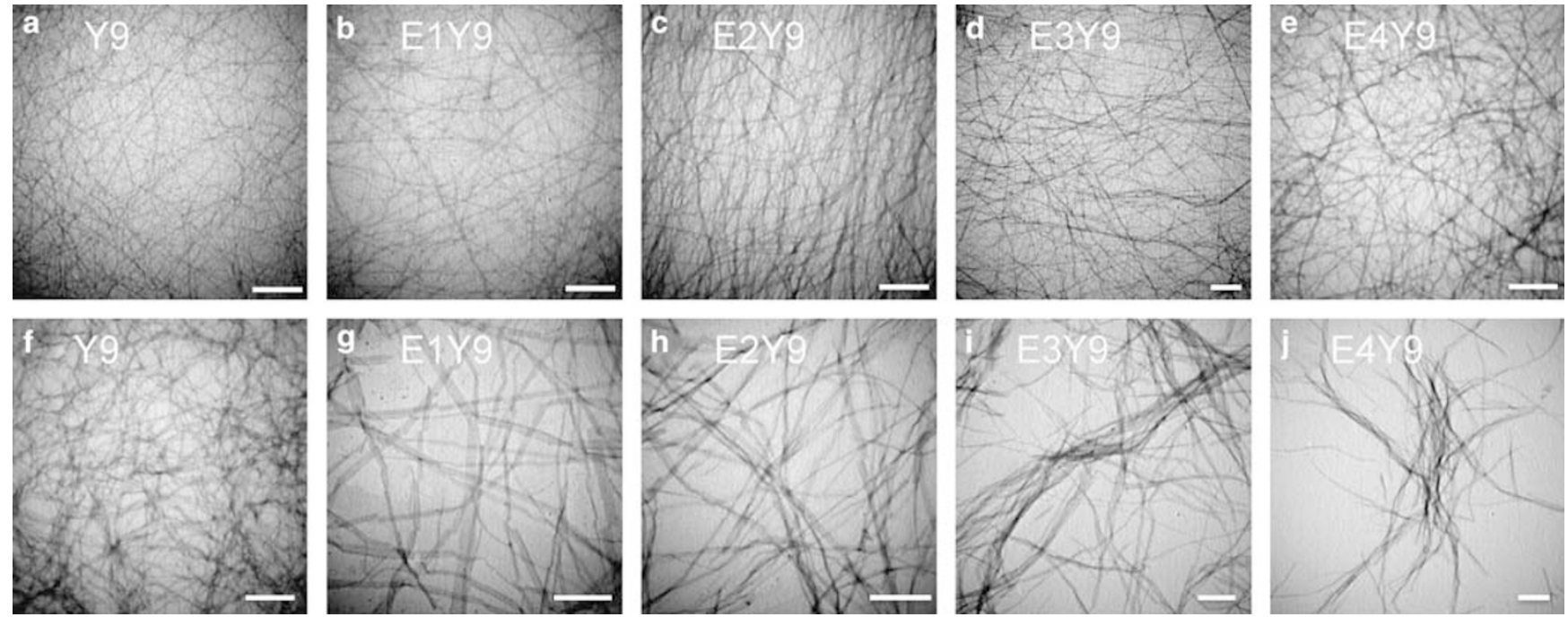

Figure 3 TEM images of the peptide nanofibers with the networked structures. Peptide nanofibers were incubated with a concentration of $400 \mu \mathrm{m}(\mathrm{a}-\mathrm{e})$ without and $(\mathbf{f}-\mathbf{j})$ with $\mathrm{Ca}^{2}+(4.0 \mathrm{~mm})$. The peptide names are shown in the each image. Glu-conjugated peptide (EnY9) nanofibers show different morphologies when $\mathrm{Ca}^{2}+$ was added. The widths of the nanofibers with $\mathrm{Ca}^{2+}$ were several times wider than those of the nanofibers without $\mathrm{Ca}^{2+}$. The entanglement degree increased with the conjugation number of the Glu residue. All scale bars represent $500 \mathrm{~nm}$. 

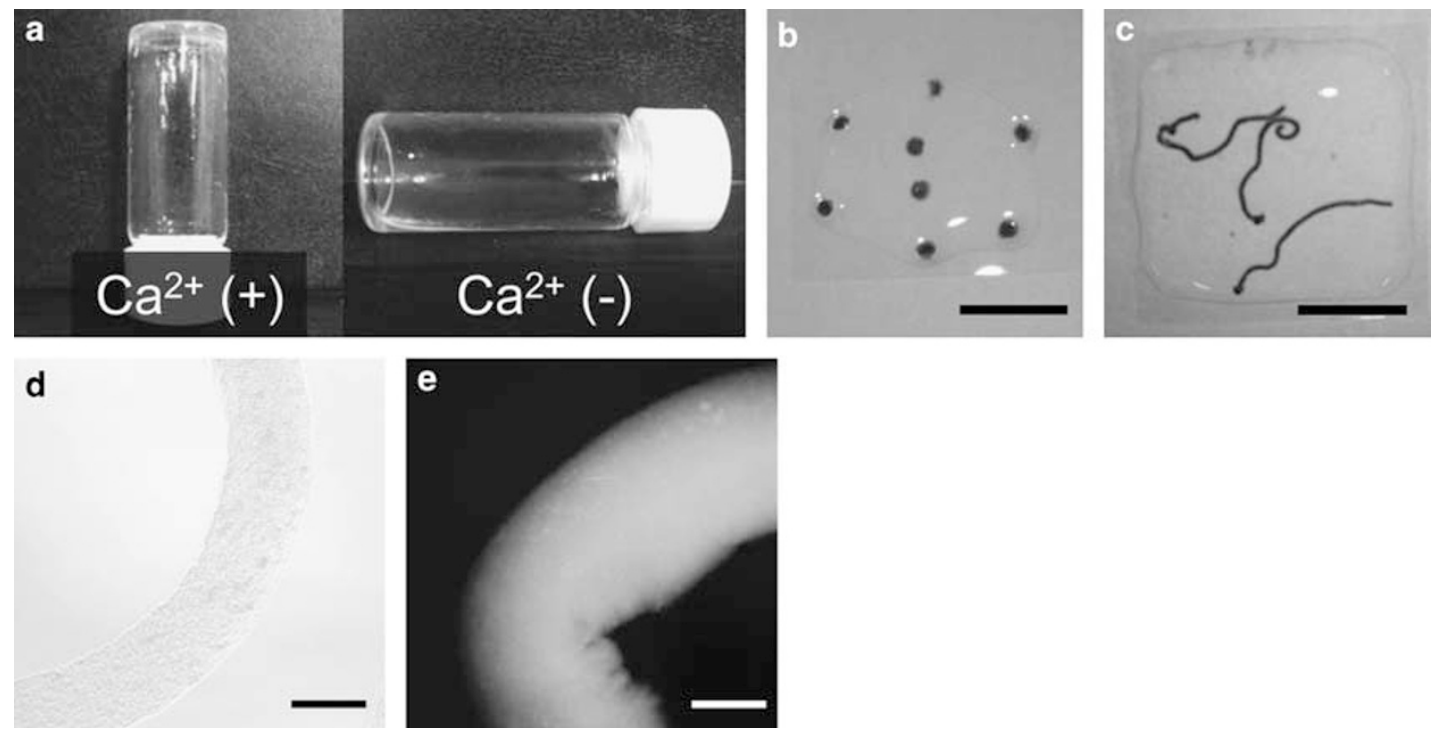

Figure 4 Photographs and microscopic images of the gel drops and strings. (a) E1Y9 peptide nanofibers with and without Ca ${ }^{2}+$ in vial tubes. The peptide solution $(0.75 \mathrm{wt} \%)$ in the presence of $\mathrm{Ca}^{2}+$ self-assembled into self-supporting hydrogels. (b, c) Optical photographs of E1Y9 peptide gel drops (b) and strings (c) constructed by injection of the peptide solution into $\mathrm{Ca}^{2+}$ solutions. The scale bars represent $1 \mathrm{~cm}$. (d, e) Bright-field (d) and fluorescence (e) microscopic images of the gel strings. The scale bars represent $500 \mu \mathrm{m}$. In the fluorescence image, the peptide nanofibers were stained by ThT.

conjugated Glu residues preferentially interact with $\mathrm{Ca}^{2+}$, which leads to intermolecular interactions of peptides via $\mathrm{Ca}^{2+}$. In other words, the Glu residues in the designed peptides were effective for $\beta$-structure and nanofiber formation due to the interactions with $\mathrm{Ca}^{2+}$.

\section{$\mathrm{Ca}^{2+}$-dependent nanofiber formation and hydrogelation}

In the previous section, the formation abilities of the peptides for $\beta$-structures and nanofibers were spectroscopically characterized. The fluorescence intensities, however, did not provide direct evidence for the nanofiber formation. To better understand the fiber formation abilities, direct observation should be performed by TEM analyses. Y9 and EnY9 peptide nanofibers were incubated with and without $\mathrm{Ca}^{2+}$ and applied to the TEM grid. Highly networked and disentangled peptide nanofibers constructed by Y 9 or EnY9 peptides were observed (Figures 3a-e). All nanofibers showed a similar morphology with a width of approximately $10-20 \mathrm{~nm}$ and a length of several micrometers, suggesting that the conjugated Glu residues do not affect the self-assembling ability in the absence of $\mathrm{Ca}^{2+}$. When $\mathrm{Ca}^{2+}$ was added to the peptide solutions, the morphologies of EnY9 nanofibers were drastically changed (Figures $3 \mathrm{~g}-\mathrm{j}$ ), even though that of the original Y9 nanofiber was not changed (Figure 3f). The EnY9 peptides in the presence of $\mathrm{Ca}^{2+}$ were self-assembled into nanofibers with widths of $30-90 \mathrm{~nm}$ and lengths of several micrometers. The addition of $\mathrm{Ca}^{2+}$ resulted in increases of the width, supporting interactions of $\mathrm{Ca}^{2+}$ with the peptides. The $\mathrm{Ca}^{2+}$ might act as a cross-linking reagent for intermolecular interaction of the peptides, leading to the construction of thicker nanofibers. E1Y9 nanofibers are well disentangled, just as the original Y9 nanofibers are, although the number of entangled nanofibers increased with an increasing number of Glu residues. In particular, E4Y9 nanofibers are strongly entangled with each other (Figure 3j). These results demonstrated that the Glu residues introduced to the $\mathrm{Y} 9$ peptide interact with $\mathrm{Ca}^{2+}$, that is, the introduction of Glu residues afforded a responsive ability to $\mathrm{Ca}^{2+}$ for the nanofiber assembly.

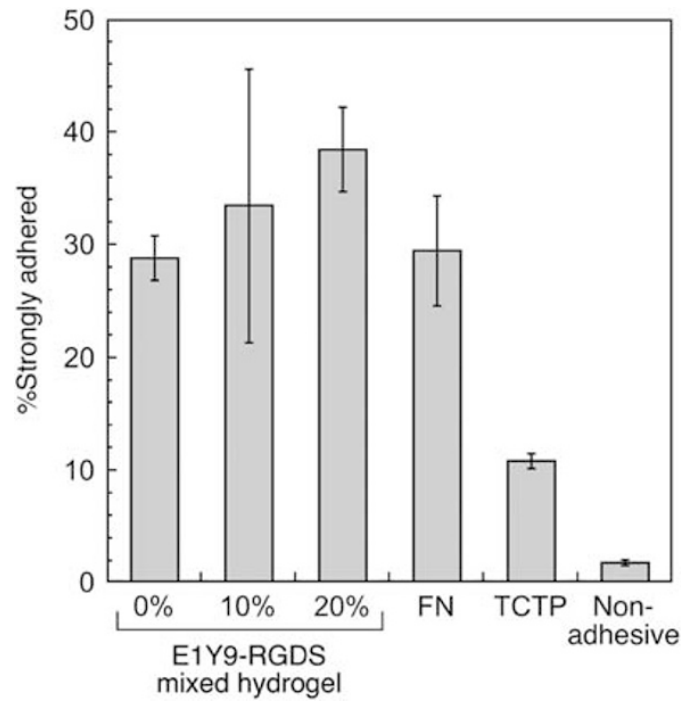

Figure 5 Percentages of strongly attached 3T3-L1 cells. 3T3-L1 cells were incubated on the flat hydrogels composed of E1Y9 peptides containing 0 , 10 or 20\% E1Y9-RGDS (Ac-EYEYKYEYKY-Aeea-RGDS-NH $\mathrm{N}_{2}$ ) peptides, fibronectin (FN), tissue culture-treated plates (TCTP) or nonadhesive plate surfaces in Dulbecco's modified Eagle's medium containing $5 \mathrm{~mm} \mathrm{Ca}^{2+}$. By comparing the amplified cell numbers and the cell numbers after washing, the percentages of strongly adhered cells were determined.

The peptide solutions at a higher concentration $(0.75 \mathrm{wt} \%$, approximately $5 \mathrm{~mm}$ ) with and without $\mathrm{Ca}^{2}+(5$ equiv) were prepared to evaluate the hydrogelation abilities. All peptide solutions in the absence of $\mathrm{Ca}^{2+}$ and both original Y9 peptide solutions yielded subtly viscous solutions (Supplementary Figure S1). In contrast, EnY9 peptide solutions with $\mathrm{Ca}^{2+}$ yielded highly viscous solutions due to the interactions between the peptides and $\mathrm{Ca}^{2+}$ (Supplementary 
Figure S2). In particular, the E1Y9 peptide solution behaved as a selfsupporting hydrogel, as shown by the vial inversion test (Figure 4a), demonstrating that the E1Y9 peptide has a highly responsive ability to phase transition from a solution to a hydrogel via the addition of $\mathrm{Ca}^{2+}$. Considering the wider width and disentangled states of the E1Y9 nanofiber, the morphology is appropriate for construction of hydrogels. Owing to the E1Y9 peptide having only one additional Glu residue that can bind to $\mathrm{Ca}^{2+}, \mathrm{Ca}^{2}+$ should act as a cross-linker when interacting with E1Y9 peptides, resulting in hydrogelation. Although E2-E4Y9 peptides showed higher abilities in fiber formation in the ThT assay than E1Y9, a longer Glu sequence might weaken the hydrogelation ability, possibly due to an increase in hydrophilicity. To apply the excellent $\mathrm{Ca}^{2}+$ responsive hydrogelation ability of E1Y9 peptides, the E1Y9 solution $(2.0 \mathrm{wt} \%)$ in a higher concentration containing Coomassie brilliant blue or ThT was injected into a $\mathrm{Ca}^{2+}$ solution $(100 \mathrm{~mm})$. As a result, gel drops and strings composed of the E1Y9 peptides were generated (Figures $4 \mathrm{~b}-\mathrm{e}$ ). Based on the optical and fluorescence staining, it was clearly demonstrated that the drops and strings were composed of peptides (Figures $4 \mathrm{~b}-\mathrm{e}$ ). As the E1Y9 hydrogels were constructed by injection of the sol-state solution into a $\mathrm{Ca}^{2+}$ solution with a faster process after formation of a viscous sol solution with a slower self-assembly process, hydrogels with various shapes could be generated. That is, the hydrogels have high formability for tissue engineering, in which various shapes are desired for $3 \mathrm{D}$ cell culturing.

\section{Cell adhesion on hydrogels}

To construct cell-adhesive hydrogels composed of the peptide nanofibers, the RGDS sequence, which is well known to introduce cell adhesion, was conjugated to $C$-termini of E1Y9 peptides via Aeea as a spacer, and the newly designed peptide was named E1Y9RGDS peptide. IR, TEM and hydrogelation studies suggested that mixing of up to $20 \%$ of E1Y9-RGDS with E1Y9 did not affect to the nanofiber assembly and hydrogel formation (data not shown). Thus,
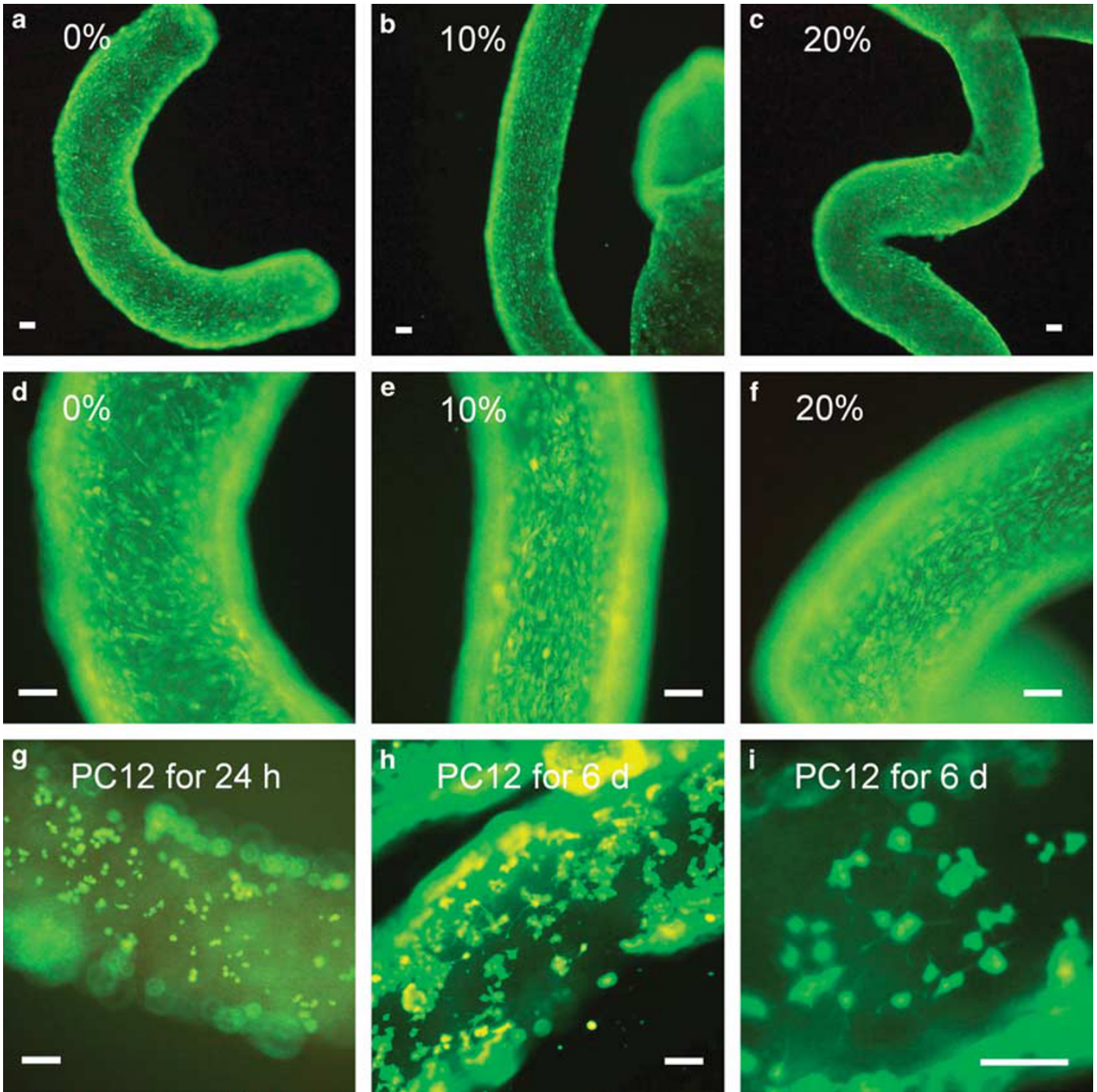

Figure 6 Fluorescence microscopic images of cell-adhered peptide gel strings. Cells were cultured in Dulbecco's modified Eagle's medium containing 5 mm $\mathrm{Ca}^{2+}$. All scale bars represent $100 \mu \mathrm{m}$. (a-f) 3T3-L1 cells were cultured on the gel strings composed of E1Y9 peptides containing 0, 10 or 20\% E1Y9RGDS peptides. The contents of the gel strings are shown in the images. The cells were clearly adhered on the strings. Well-extended states were observed in the high-magnification images ( $\mathbf{d}-\mathbf{f})$. (g-i) PC12 cells were cultured on the gel strings with differentiation induction for $24 \mathrm{~h}(\mathbf{g})$ and $6 \mathrm{~d}$ (days) (h, i). The cells were clearly increased with the incubation and were well differentiated. 
E1Y9-RGDS peptide was used as a mixed substrate with E1Y9 peptide. For cell adhesive materials, a high cell-survival rate on the material is critically important. Flat hydrogels were constructed on the 24-well non-adhesive-treated plate surfaces. A live/dead assay for 3T3L1 cells using calcein-AM and propidium iodide was performed on the hydrogel and TCTP surfaces, respectively. Fluorescence microscopic images clearly demonstrated the high survival rates on the peptide hydrogels compared with commercially available TCTP surfaces (Supplementary Figure S3). Furthermore, 3T3-L1 cells were cultured on the peptide hydrogel, fibronectin immobilized, TCTP or nonadhesive plate surfaces in the absence of serum-free Dulbecco's modified Eagle's medium. Cells were propagated by culture on all surfaces. Strongly adhered cells were estimated by comparing the fluorescence before and after washing (Figure 5). The peptide hydrogels showed three times higher cell-adhesive abilities compared with TCTP surfaces and comparable abilities with the fibronectin immobilized surface, which is a native adhesive protein surface. Interestingly, the adhered cell numbers on each peptide hydrogel were almost the same. Therefore, the content (percentage) of E1Y9-RGDS peptides does not have a major role in cell adhesive abilities, implying that some proportion of RGDS moieties might exist in the interior of the hydrogels. In other words, an E1Y9 peptide-alone hydrogel surface has an activity high enough for cell adhesion. The cell-adhesive ability might be derived from electrostatic interactions and/or hydrophobic effects between cell and peptide-gel surfaces. It was worth noted that hydrogels composed of charged peptide nanofibers have cell-adhesive abilities due to the electrostatic interactions with cell surfaces. ${ }^{28,29}$

To use the high formability of the hydrogels for tissue engineering, cells were cultured on the constructed gel strings in non-adhesive microtiter plates. After 4 days of culturing the3T3-L1 cells, fluorescence microscopic analyses were performed (Figures 6a-c). Cells were homogeneously attached on all the peptide gel strings, which were several millimeters long. High-magnification images suggested that higher contents of E1Y9-RGDS resulted in increasingly high cell densities (Figures 6d-f). Similar differences in cell adhesion were also observed on the flat peptide hydrogels, as shown in Figure 5. Therefore, it was suggested that a portion of the RGDS moiety was effectively exposed on the hydrogel surfaces, leading to higher-density adhesions. That is, cell densities may be controlled by changing the mixing ratio of RGDS-peptide. When the cells were cultured in $\mathrm{Ca}^{2+}$-free phosphate-buffered saline ( $\mathrm{pH} 7.4$ ), sufficient cell adhesion did not occur due to lack of bivalent cations. Moreover, other cell lines (PC12), which can be differentiated to nerve-like cells, were also cultured on the hydrogels. After $24 \mathrm{~h}$ incubation, the cells were adhered on the gel strings (Figure $6 \mathrm{~g}$ ). After further culturing for 6 days with differentiation induction, neurite elongation of differentiated PC12 cells was observed (Figures $6 \mathrm{~h}$ and i). These results strongly suggested that the novel peptide hydrogels composed of E1Y9 and E1Y9-RGDS peptides can be powerful scaffolds that can be formed into the shapes required for $3 \mathrm{D}$ culturing of various cell lines in controlled differentiation states.

\section{CONCLUSIONS}

We demonstrated $\mathrm{Ca}^{2+}$-induced formation of a peptide hydrogel by triggered cross-linking and subsequent self-assembly to nanofibers. The novel one Glu residue-conjugated $\beta$-sheet peptides, E1Y9, underwent hydrogelation on cue in response to $\mathrm{Ca}^{2+}$. The hydrogels were constructed by disentangled and wider nanofibers than the original Y9 nanofibers and E1Y9 nanofibers in the absence of $\mathrm{Ca}^{2+}$. The additional Glu residues in E1-E4Y9 peptides were effectively used for interaction with $\mathrm{Ca}^{2+}$, and the morphologies of the peptide nanofibers were changed. Introduced Glu numbers were important for the nanofiber morphologies following hydrogelation, and one Glu residue has the best ability to construct peptide hydrogels, as described above. Hydrogelation of the E1Y9 peptides was performed by the formation of a viscous sol state with a slower self-assembly process, followed by conjugation with $\mathrm{Ca}^{2+}$ solutions with a faster process. Therefore, the peptide hydrogels have the advantage of higher formability, which can be used to construct the desired shapes. In fact, gel strings can be easily created by the simple injection method. Cell culture experiments on the hydrogels were successfully performed with a low toxicity. Furthermore, the hydrogel was demonstrated to show adhesive abilities much higher than the cell culture plate and with a level similar to fibronectin surfaces. Different cell lines, 3T3-L1 and PC12, could be propagated and attached on the gel strings. Thus, the novel peptide-based materials will facilitate development studies for 3D cell culturing using various desired shapes, which will advance the field of novel tissue engineering.

\section{ACKNOWLEDGEMENTS}

We thank Prof E Kobatake and Dr M Mie (Tokyo Institute of Technology) for help with the cell experiments and for insightful discussions. This work is supported by a Grant-in-Aid for Scientific Research on Innovative Areas of 'Fusion Materials'(no. 2206) from the Ministry of Education, Culture, Sports, Science and Technology, Japan. TS is grateful to the Japan Society for the Promotion of Science (JSPS) for a Research Fellowship for Young Scientists.

1 Zhang, S. Fabrication of novel biomaterials through molecular self-assembly. Nat. Biotechnol 21, 1171-1179 (2003).

2 Zhao, X. \& Zhang, S. Molecular designer self-assembling peptides. Chem. Soc. Rev. 35, 1105-1110 (2006)

3 Rajagopal, K. \& Schneider, J. Self-assembling peptides and proteins for nanotechnological applications. Curr. Opin. Struct. Biol. 14, 480-486 (2004).

4 Boyle, A. \& Woolfson, D. De novo designed peptides for biological applications. Chem Soc. Rev. 40, 4295-4601 (2011).

5 Kodama, H., Matsumura, S., Yamashita, T. \& Mihara, H. Construction of a protein array on amyloid-like fibrils using co-assembly of designed peptides. Chem. Commun. 2876-2877 (2004)

6 Reches, M. \& Gazit, E. Casting metal nanowires within discrete self-assembled peptide nanotubes. Science 300, 625-632 (2003).

7 Paramonov, S., Jun, H. W. \& Hartgerink, J. Self-assembly of peptide-amphiphile nanofibers: the roles of hydrogen bonding and amphiphilic packing. J. Am. Chem. Soc 128, 7291-7299 (2006).

8 Chang, J., Peng, X.- F., Hijji, K., Cappello, J., Ghandehari, H., Solares, S. \& Seog, J. Nanomechanical stimulus accelerates and directs the self-assembly of silk-elastin-like nanofibers. J. Am. Chem. Soc. 133, 1745-1747 (2011).

9 Lamm, M., Rajagopal, K., Schneider, J. \& Pochan, D. Laminated morphology of nontwisting beta-sheet fibrils constructed via peptide self-assembly. J. Am. Chem. Soc 127, 16692-17000 (2005).

10 Lamm, M. S., Sharma, N., Rajagopal, K., Beyer, F. L., Schneider, J. P. \& Pochan, D. J. Laterally spaced linear nanoparticle arrays templated by laminated beta-sheet fibrils. Adv. Mater. 20, 447-451 (2008).

11 Matsuura, K., Murasato, K. \& Kimizuka, N. Artificial peptide-nanospheres selfassembled from three-way junctions of beta-sheet-forming peptides. J. Am. Chem. Soc. 127, 10148-10157 (2005)

12 Ghosh, S., Reches, M., Gazit, E. \& Verma, S. Bioinspired design of nanocages by selfassembling triskelion peptide elements. Angew. Chem. Int. Ed. 46, 2002-2006 (2007)

13 Hartgerink, J. D., Beniash, E. \& Stupp, S. I. Self-assembly and mineralization of peptide-amphiphile nanofibers. Science 294, 1684-1688 (2001).

14 Maltzahn, G., Vauthey, S., Santoso, S. \& Zhang, S. Positively charged surfactant-like peptides self-assemble into nanostructures. Langmuir 19, 4332-4337 (2003).

15 Amalia, A., Mark, B., Neville, B., Lisa, M. C. \& Andrew, E. S. Self-assembling peptide polyelectrolyte beta-sheet complexes form nematic hydrogels. Anegw. Chem. Int. Ed. 42, 5603-5606 (2003).

16 Smith, A., Williams, R., Tang, C. \& Coppo, P. Fmoc-diphenylalanine self assembles to a hydrogel via a novel architecture based on pi-pi interlocked beta-Sheets. Adv. Mater 20, 37-41 (2008).

17 Bowerman, C. \& Nilsson, B. A reductive trigger for peptide self-assembly and hydrogelation. J. Am. Chem. Soc. 132, 9526-9533 (2010).

18 Matsumura, S., Uemura, S. \& Mihara, H. Fabrication of nanofibers with uniform morphology by self-assembly of designed peptides. Chem. Eur. J 10, 2789-2794 (2004) 
19 Matsumura, S., Uemura, S. \& Mihara, H. Construction of biotinylated peptide nanotubes for arranging proteins. Mol. BioSyst. 1, 146-148 (2005).

20 Sawada, T., Takahashi, T. \& Mihara, H. Affinity-based screening of peptides recognizing assembly states of self-assembling peptide nanomaterials. J. Am. Chem. Soc. 131, 14434-14475 (2009).

21 Miyachi, A., Takahashi, T., Matsumura, S. \& Mihara, H. Peptide nanofibers modified with a protein by using designed anchor molecules bearing hydrophobic and functional moieties. Chem. Eur. J 16, 6644-6694 (2010).

22 Sawada, T. \& Mihara, H. Dense surface functionalization using peptides that recognize differences in organized structures of self-assembling nanomaterials. Mol. BioSyst. $\mathbf{8}$, 1264-1274 (2012).

23 Mart, R., Osborne, R. \& Stevens, M. Peptide-based stimuli-responsive biomaterials. Soft Matter 2, 822-835 (2006).

24 White, P. D. \& Chan, W. C. in Fmoc Solid Phase Peptide Synthesis: A Practical Approach (eds White, P. D. \& Chan, W. C.) 41-76 (Oxford University Press, 2000).
25 Haris, P. \& Chapman, D. The conformational analysis of peptides using Fourier transform IR spectroscopy. Biopolymers 37, 251-263 (1995).

26 Srisailam, S., Kumar, T., Rajalingam, D., Kathir, K., Sheu, H.- S, Jan, F- J, Chao, P. C. \& Yu, C. Amyloid-like fibril formation in an all beta-barrel protein. Partially structured intermediate state(s) is a precursor for fibril formation. J. Biol. Chem 278, 1770117710 (2003).

27 Moses, J. P., Satheeshkumar, K., Murali, J., Alli, D. \& Jayakumar, R. Self-assembly of the synthetic polymer (Leu-Glu)n: an amyloid-like structure formation. Langmuir 19, 3413-3418 (2003).

28 Holmes, T., de Lacalle, S., Su, X., Liu, G., Rich, A. \& Zhang, S. Extensive neurite outgrowth and active synapse formation on self-assembling peptide scaffolds. Proc. Natl. Acad. Sci. USA. 97, 6728-6761 (2000).

29 Kretsinger, J., Haines, L., Ozbas, B., Pochan, D. \& Schneider, J. Cytocompatibility of self-assembled beta-hairpin peptide hydrogel surfaces. Biomaterials 26, 5177-5263 (2005).

Supplementary Information accompanies the paper on Polymer Journal website (http://www.nature.com/pj) 